\title{
The effects of a pressure extraction system on the quality parameters of different virgin pistachio (Pistacia vera L. var. Larnaka) oils
}

\author{
By M. Álvarez-Ortí ${ }^{*}$, C. Quintanilla, E. Sena, A. Alvarruiz and J.E. Pardo \\ E.T.S.I. Agrónomos. Departamento de Producción Vegetal y Tecnología Agraria. \\ Campus Universitario s/n, 02071-Albacete (Spain) \\ ${ }^{*}$ Corresponding author: manuel.alvarez@uclm.es
}

\section{RESUMEN}

\begin{abstract}
Efecto del sistema de extracción por presión en los parámetros de calidad de diferentes aceites vírgenes de pistacho (Pistacia vera L. var. Larnaka).
\end{abstract}

El pistacho es una magnífica fuente de aceite, puesto que a su alto contenido en materia grasa se añaden una elevada proporción de ácidos grasos insaturados y otros compuestos bioactivos como los polifenoles o los compuestos fenólicos. Se ha analizado el rendimiento y los parámetros de calidad del aceite extraído de cuatro tipos de pistacho de diferente calidad, usando dos tipos de prensas (hidráulica y de tornillo). El rendimiento de la extracción fue mayor cuando se empleó la prensa de tornillo, especialmente cuando los pistachos de mayor calidad (pistachos más grandes) se emplearon para la extracción del aceite $(40 \pm 2,12 \%)$. Con la prensa hidráulica, el rendimiento fue de alrededor del 30\% para todos los tipos de pistacho. El color fue más oscuro en todas las muestras de aceite obtenido a partir de la prensa de tornillo. No se apreciaron diferencias significativas en cuanto a los valores de acidez libre y los parámetros $\mathrm{K}_{270} \mathrm{y}$ $\mathrm{K}_{232}$ cuando se emplearon los pistachos de mayor calidad. En los pistachos de menor calidad, estos tres parámetros presentaron valores superiores, especialmente en los aceites obtenidos en la prensa de tornillo. Por otro lado, la estabilidad oxidativa fue mayor en los aceites obtenidos a partir de pistachos de la mayor calidad, independientemente del sistema de extracción utilizado. En los aceites obtenidos a partir de pistachos de menor calidad, la estabilidad oxidativa decreció significativamente.

PALABRAS CLAVE: Aceite - Calidad - Estabilidad oxidativa - Pistacia vera - Pistacho.

\section{SUMMARY}

The effects of a pressure extraction system on quality the parameters of different virgin pistachio (Pistacia vera L. var. Larnaka) oils.

Pistachios are a good source for oil extraction as they are rich in unsaturated fatty acids and other bioactive components like polyphenols and phenolic compounds. The yield and quality parameters of the oil extracted from four batches of pistachios with different sizes were analyzed. Two different pressure systems (screw press and hydraulic press) were used for oil extraction. The yield was higher when the screw press was used, especially when the highest quality pistachios (larger pistachios) were used to extract the oil $(40 \pm 2.12 \%)$. With the hydraulic press, the yield was around $30 \%$ for all pistachio types. The color of the oils extracted with the screw press was darker than the oil extracted with the hydraulic press in all types of pistachios used. No significant differences were found in the acidity, $\mathrm{K}_{270}$, and $\mathrm{K}_{232}$ values when high quality pistachios were used. When lower quality pistachios (smaller pistachios) were used, the values of these three parameters increased in comparison with larger pistachios. On the other hand, oil samples from lower quality pistachios obtained by the screw press showed the highest values. The oxidative stability was higher in the samples of oil from high quality pistachios, with no differences in regard to the extraction system. When lower quality pistachios were used, the oxidative stability was significantly lower.

KEY-WORDS: Oil - Oxidative stability - Pistachio Pistacia vera - Quality.

\section{INTRODUCTION}

Nuts are nutrient dense foods rich in unsaturated fatty acids and other bioactive compounds like tocopherols, phytosterols, and phenolic compounds, with wide-ranging cardiovascular and metabolic benefits (Ros, 2010). Among these nuts, the pistachio (Pistacia vera L.) is an increasingly important crop, and one of the favourite nut trees in the world. It is widely cultivated in arid zones of the eastern Mediterranean and the US, and recently it is being introduced successfully in hot dry regions of Spain. Pistachios contain about $45-57 \%$ oil, with a high proportion of unsaturated fatty acids like oleic, linoleic and linolenic acids (Arena et al., 2007; Tavakolipour et al., 2010; Tsantili et al., 2010). In addition, pistachios are a rich source of phytosterols and phenolic compounds (Phillips et al., 2005; Tomaino et al., 2010). These components have beneficial effects on human health, as phytosterols have been shown to reduce blood cholesterol and decrease the risk of certain types of cancer (Awad and Fink, 2000; Ostlund, 2004), whereas the phenolic compounds show antioxidant properties (Gentile et al., 2007).

Edible oils play an important role in the food industry due to their nutritional properties and their influence on the taste and smell of food. The oils extracted from different seeds or nuts are an interesting culinary addition to provide new 
organoleptic properties from a sensory point of view (Uriarte et al., 2011).

Generally, pistachio oil is extracted using solvents such as hexane or diethyl ether (Bellomo et al., 2009; Conte et al., 2011). However, extraction with solvents may produce unpleasant smells and tastes in the resulting oil, which make it unsuitable for human consumption unless it is subjected to a refining process. In this aspect, pressure systems are more suitable for oil extraction as no chemical products are involved in the process. This extraction system produces a more pleasant product that may be used directly for cooking or fresh consumption, with all the benefits for human health derived from the chemical composition of pistachios.

In this work, the oil was extracted from pistachios by means of pressure. Two systems were used: screw press and hydraulic press. The yield of both methods and the quality characteristics of the pistachio oil extracted with the two systems were analyzed in order to determine possible changes occurring in the oil derived from the extraction systems. In addition, four different batches of pistachios differing in size were analyzed in order to determine their possible use for oil production in the industry: one commercial and three non commercial

\section{MATERIALS AND METHODS}

\subsection{Sampling}

Pistachios were kindly provided by "Pistachos de la Mancha" factory (Balazote, Albacete, Spain). They were collected from orchards surrounding the factory. Four batches of pistachios (Pistacia vera L., var. Larnaka) were used for this analysis: a commercial batch (labeled as Larnaka), and three batches of pistachios which are unsuitable for commercialization due to their small size or to the presence of defects like dark spots or broken kernels, labeled as $\mathrm{A}, \mathrm{B}$, and $\mathrm{C}$. In Table 1 the average sizes of the different batches of pistachios are shown. The quality of pistachios is related to their size. Sample $C$ is considered to have the lowest quality due to the small size of the kernels and the presence of dark spots, while the sample

Table 1

Weight, width and length of the different types of pistachios used

\begin{tabular}{lccc}
\hline Type & Weight $(\mathbf{g})$ & Width $(\mathbf{m m})$ & $\begin{array}{c}\text { Length } \\
(\mathbf{m m})\end{array}$ \\
\hline Larnaka & $0.59 \pm 0.10$ & $8.80 \pm 0.71$ & $16.3 \pm 1.64$ \\
A & $0.54 \pm 0.11$ & $8.45 \pm 0.60$ & $16.2 \pm 1.55$ \\
B & $0.42 \pm 0.08$ & $8.10 \pm 0.57$ & $15.4 \pm 1.78$ \\
C & $0.28 \pm 0.04$ & $7.00 \pm 0.53$ & $13.5 \pm 1.27$ \\
\hline
\end{tabular}

The values represent the average and standard deviation of 100 pistachios. labeled as Larnaka is considered to have the highest quality, as the kernels are the largest ones and with complete absence of dark spots. Samples $A$ and $B$ are considered to have intermediate quality.

Moisture content was calculated by the difference in weight of $5 \mathrm{~g}$ sample before and after complete drying at $105^{\circ} \mathrm{C}$ overnight using a desiccation oven with forced ventilation.

The oil was extracted with two different pressure systems (Figure 1): hydraulic press (Hidráulica Dumont S.A., Santiago, Chile) and screw press Komet Oil Press CA59G (IBG Monforts Oekotec $\mathrm{GmbH}$ \& Co. KG, Mönchengladbach, Germany). For the hydraulic press, $200 \mathrm{~g}$ of pistachios were previously ground and subjected to a pressure of $60 \mathrm{~kg} \mathrm{~cm}^{-2}$ for $10 \mathrm{~min}$. For the screw press, $200 \mathrm{~g}$ of pistachios were introduced directly into the press. The tip was previously heated to ensure the correct extraction procedure. In both cases, 3 replicates were prepared for each type of pistachio.

After oil extraction, a centrifugation step was carried out in order to eliminate the remaining solid residues from the samples. The oil samples were stored at $4{ }^{\circ} \mathrm{C}$ in dark glass bottles to avoid oxidation until analysis. The analysis of samples was performed in a period of less than two weeks after oil extraction.

\subsection{Analytical determinations}

The color of the samples was measured with a Minolta CR-200 colorimeter (Minolta Co., Ltd. Osaka, Japan). The illuminant used was D65, with a viewing angle of $2 \circ$. The tristimulus values
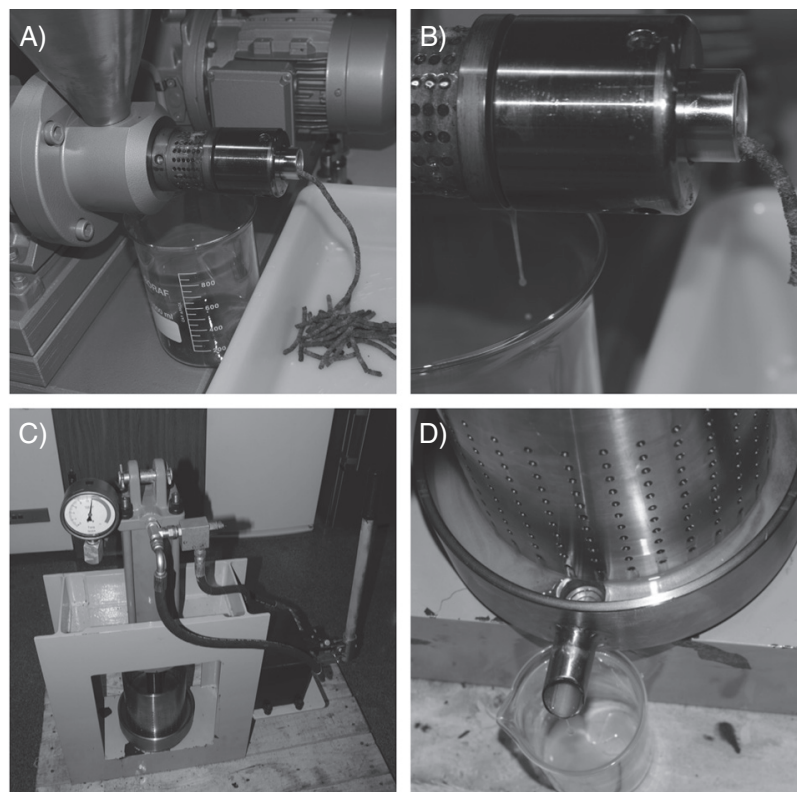

Figure 1

A) Screw press Komet Oil Press CA59G (IBG MonfortsOekotec $\mathrm{GmbH} \&$ Co. KG, Mönchengladbach, Germany).

B) Details of oil extraction with the screw press.

C) Hydraulic press (Hidráulica Dumont S.A., Santiago, Chile).

D) Details of oil extraction with the hydraulic press. 
obtained were used to calculate the CIELAB chromatic coordinates $L^{*}$ (lightness), $a^{*}$ (redness), and $\mathrm{b}^{*}$ (yellowness), and color attributes $\mathrm{C}^{*}$ (chroma) and $h^{*}$ (hue angle), as recommended by the Commission Internationale de l'Eclairage (CIE, 1986; McGuire, 1992).

Free acidity, given as \% of oleic acid, was determined by titration of a solution of oil dissolved in ethanol/ether (1:1) with $0.1 \mathrm{M}$ potassium hydroxide ethanolic solution (EEC, 1991).

$\mathrm{K}_{270}$ and $\mathrm{K}_{232}$ extinction coefficients were calculated from absorbance at 270 and $232 \mathrm{~nm}$, respectively, with a UV/VIS spectrophotometer Jasco V-530 (Jasco Analitica Spain, Madrid, Spain), and a path length of $1 \mathrm{~cm}$. For $\mathrm{K}_{270}$, a $1 \%$ solution of oil in cyclohexane was used, while for $\mathrm{K}_{232}$ a $0.5 \%$ solution of oil in cyclohexane was used (EEC, 1991).

Oxidative stability was evaluated by the rancimat method (Gutiérrez, 1989). Stability was expressed as the oxidation induction time (hours), measured with the Rancimat 743 apparatus (Metrohm Co., Basel, Switzerland). An oil sample of $3.5 \mathrm{~g}$ was used, warmed to $100^{\circ} \mathrm{C}$ under an air flow of $10 \mathrm{~L} \mathrm{~h}^{-1}$.

The oil content of the pistachios was measured by a Soxhlet extractor (BUCHI Labortechnik AG, Flawil, Switzerland), using petroleum ether as solvent, for an extraction period of $6 \mathrm{~h}$ (AOAC, 1990).

\subsection{Statistical analysis}

Significant differences among varieties were determined by an analysis of variance, which applied a Duncan test with a 95\% significance level $(\mathrm{P}<0.05)$, using the SPSS programme, release 11.5 for Windows.

\section{RESULTS AND DISCUSSION}

\subsection{Yield}

The oil content of the pistachios was measured with a Soxhlet extractor. The measurements showed a percentage of fat between $54 \%$ in the Larnaka sample and $40 \%$ in sample C, with intermediate values for samples A and B (48\% and $47 \%$, respectively). These values agree with those reported by other authors (Arena et al., 2007; Tsantili et al., 2010; Panahi and Khezri, 2011), although certain ecotypes have been reported to have higher fat content values of up to $80 \%$ (Ghrab et al., 2010). In addition, the moisture was also measured. All the samples showed values around $5 \%$. Although the moisture of natural pistachios is about $40 \%$, they are generally dried in the industry to avoid fungal proliferation, which may cause aflatoxin contamination (Bensassi et al., 2010).

The yield for both extraction systems was determined (Figure 2). The highest yield was obtained for the sample Larnaka with the screw press $(40 \pm 2.12 \%)$. In general, when both extraction methods were compared, a slight increase in the yield was observed for the screw press, although this difference was significant only when the oil was extracted from the pistachios labeled as "Larnaka". When pistachios of quality A, $B$, and $C$ were used for oil extraction, the difference in the yield for both extraction systems was not significant. In addition, the yields obtained with the screw press showed more variation. Although the screw press is considered as a cold extraction system, it requires an increase in the temperature of the tip to obtain the best results. An increase in the temperature produces a better separation of the oil, which may affect the extraction yield. In some screw presses, the temperature is difficult to control and therefore the yield presents greater variations. The hydraulic press is easier to control, as the only parameters that influence the process are the pressure (which can be easily measured by a manometer installed in the press), the time and the amount of pistachios used. Our results showed that the yield obtained for all the samples with the hydraulic press was similar (around 30\%), whereas significant differences between Larnaka and the other samples were observed with the screw press.

\subsection{Color}

The color parameters were expressed as $L^{*}$ (color intensity or lightness), $\mathrm{a}^{*}$ (redness), $\mathrm{b}^{*}$ (yellowness), $\mathrm{C}^{\star}$ (chroma, or intensity of color), and $h^{*}$ (hue angle). Figure 3 shows the values of $L^{*}, b^{*}$, $\mathrm{C}^{*}$, and $\mathrm{h}^{*}$, where significant differences between both extraction methods were found for all the samples. The oil extracted with the screw press showed lower values of the 4 parameters, indicating darker, greener oils. A similar pattern has been observed when roasted seeds are used to produce oil (Lee et al., 2004; Park et al., 2011). As stated above, the screw press requires an increase in the temperature for a correct oil extraction. It originates the change in the color of the oil to dark, probably

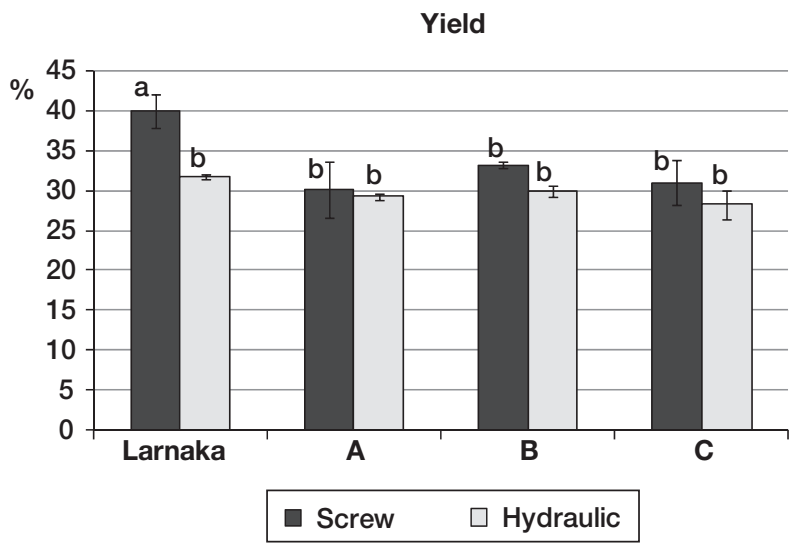

Figure 2

Yields of pistachio oil extracted with the screw press and the hydraulic press. Values represent the average and standard deviation of three replicates. Different letters on the bars indicate significant differences $(p<0.05)$ among samples (Duncan test). 
due to the appearance of products from the Maillard reaction, caramelization or phospholipid degradation (Durmaz and Gökmen, 2011; Vaidya and Choe, 2011).

In the case of the oils obtained with the hydraulic press, lower values of $L^{*}, b^{*}, C^{*}$ and $h^{*}$ were observed when lower quality pistachio samples were used (Figure 3). The quality of the pistachios, especially the presence of dark spots on the kernel, is a parameter that may influence the color of the oil when a cold extraction system with no increase in the temperature is used. Therefore, it is important to make a selection of the pistachios in order to obtain lighter and more attractive colors in the oil. When the screw press is used, the effect of the quality of pistachio is hidden due to the appearance of Maillard reaction products, resulting in more similar color in the oils extracted from different types of pistachios.

\subsection{Acidity, $\mathrm{K}_{270}, \mathrm{~K}_{232}$}

The acidity, measured as \% of oleic acid, and the extinction coefficients $\mathrm{K}_{270}$ and $\mathrm{K}_{232}$ are parameters used to estimate the quality of the oil. The values obtained for acidity, $\mathrm{K}_{270}$ and $\mathrm{K}_{232}$ are shown in Figure 4. Lower values of acidity indicate the freshness of the samples, the good quality of the oil, and no chemical or enzymatic hydrolysis of glycerolipids. The highest values of acidity were observed in sample $\mathrm{C}$ for both extraction systems. With regard to the extraction effect, the oils obtained from lower quality pistachios (B, C) showed significantly higher values of acidity when the screw press was used. Indeed, acidity may be affected by temperature, and thus, the oils obtained with the screw press present higher proportions of free fatty acids hydrolyzed from the glycerolipids. However, when high quality pistachios were used (Larnaka, A), the acidity values were similar regardless of the extraction system used. Hence, we cannot clearly exhibit the effect of temperature on the variations in acidity.

As for the ultraviolet spectrophotometric analysis, it indicates the degree of oil oxidation, with values expressed as specific extinction coefficients. The $\mathrm{K}_{232}$ and $\mathrm{K}_{270}$ are mainly indicative of the conjugation of dienes and trienes respectively. Figure 4 shows the values obtained for $\mathrm{K}_{270}$ and $\mathrm{K}_{232}$ in the oil samples extracted with the different systems. The oils extracted with the screw press present higher values of both attributes for all the samples except for the pistachios of the best quality (Larnaka), where the values are similar. In addition, differences were also observed depending on the sample analyzed. The highest values were obtained when the pistachios of the lower quality $(B, C)$ were used to extract the oil.

\subsection{Oxidative stability}

Another important parameter to study oil quality is oxidative stability. It refers to the susceptibility of the oil to lipid oxidation, which causes rancid odors
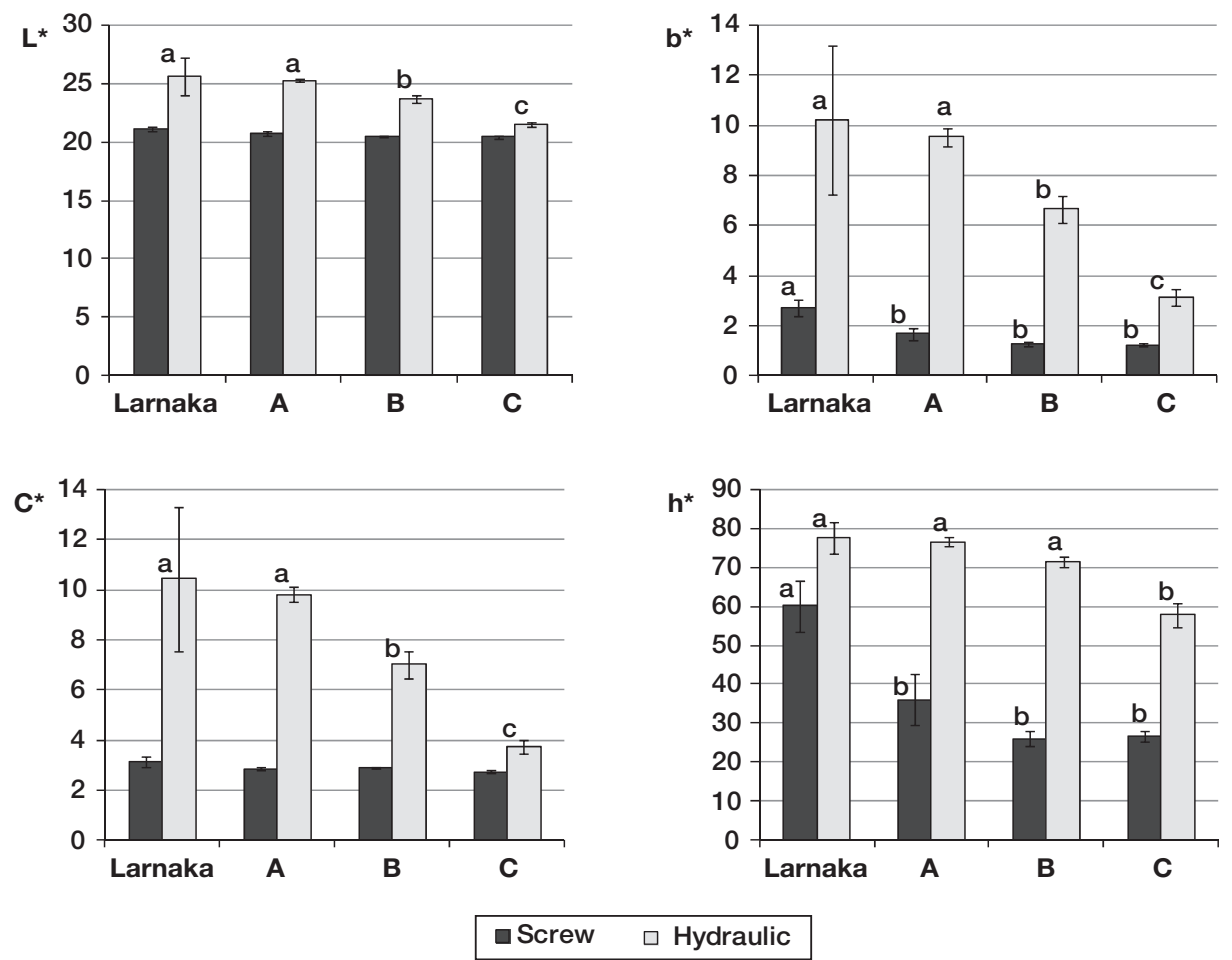

Figure 3

Color characteristics of the pistachio oil samples extracted with the screw press and the hydraulic press.

$L^{*}$ : lightness; $b^{*}$ : yellowness; $C^{*}$ : chroma; $h^{*}$ : hue angle. Values represent the average and standard deviation of three replicates. Different letters on the bars indicate significant differences $(p<0.05)$ among samples (Duncan test). 

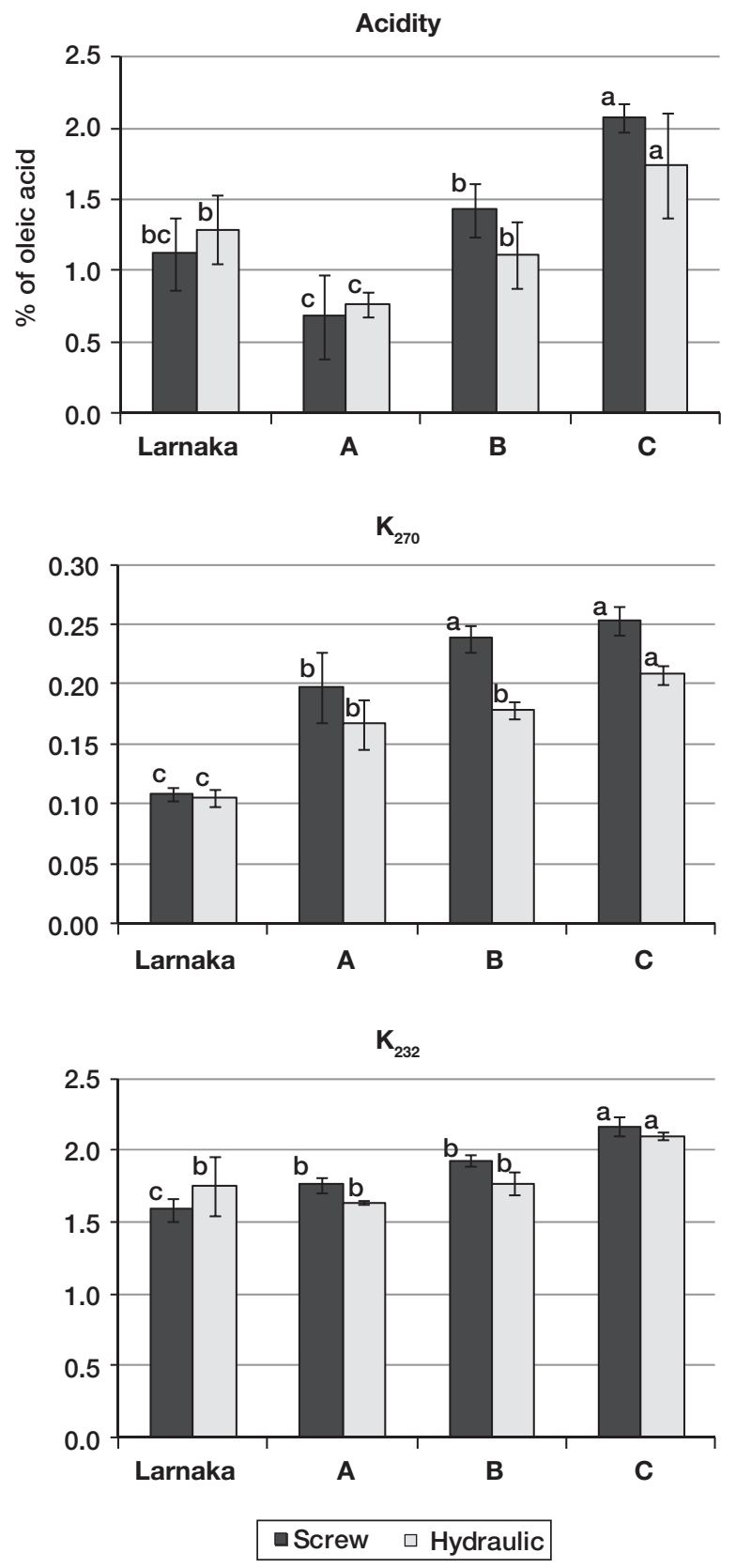

Figure 4

Acidity and spectrophotometric analysis $\left(\mathrm{K}_{270}\right.$, and $\left.\mathrm{K}_{232}\right)$ of pistachio oil samples extracted with the screw press and the hydraulic press. Values represent the average and standard deviation of three replicates.Different letters on the bars indicate significant differences $(p<0.05)$ among samples (Duncan test).

and flavors. Pistachio nuts are known to have a high concentration of polyphenols and tocopherols with antioxidant properties (Gentile et al., 2007), and pistachio oil has been reported to exhibit a high antioxidant capacity, similar to that of extra virgin olive oil (Arranz et al., 2008). The results of the oxidative stability of the virgin pistachio oils extracted with both pressure systems are shown in Table 2. The highest induction time was obtained in the commercial pistachios labeled as Larnaka, with no differences for both extraction systems (47.07 \pm 1.19 screw press; $47.76 \pm 4.70$ hydraulic press). When compared to olive oil, the most highly valued oil among edible oils, these values are similar to those obtained for oils from the varieties Arbequina or Leccino from various locations (Aguilera et al., 2005; Pardo et al., 2007), although it is considerably lower than oils from other varieties like Picual or Cornicabra (Pardo et al., 2011).

Similar values of oxidative stability have been reported in other studies (Arranz et al., 2008), and make pistachio oil one of the most stable among nut oils. Other data reported showed that pistachio oil has an oxidative stability lower than hazelnut or macadamia nut oils, but higher than walnut, peanut, cashew, pine nut and almond oils (Arranz et al., 2008; Miraliakbari and Shahidi, 2008; Kochhar and Henry, 2009). However, the oil obtained from lower quality pistachios (A, B, and C) did show significantly lower values for oxidative stability (Table 2).

It has been reported that seed roasting may improve the oxidative stability of the oils (Wijesundera et al., 2008; Durmaz and Gökmen, 2011). When the oil is extracted with the screw press, the differences in the color obtained suggest that temperature is an important factor in this system. This could explain the significant increase in the induction time of the oil from the lower quality pistachios (samples $B, C$ ) when the screw press is used, in comparison with the hydraulic press. However, as mentioned above, we found no differences when the high quality pistachios are used. On the other hand, the oil from the lowest quality pistachios (C) showed significantly lower values of oxidative stability than the oil from the highest quality pistachios (Larnaka) when the same extraction system is considered. This supports the idea that pistachio quality plays an important role with respect to oxidative stability. Indeed, the richer the pistachios are in monounsaturated fatty acids and antioxidant compounds, the more resistent the oil will be to autooxidation, whatever the temperature. This result is consistent with those of $\mathrm{K}_{232}$ and $\mathrm{K}_{270}$, since only oils from pistachios of higher quality (Larnaka) were not affected by the extraction system.

\section{CONCLUSIONS}

Two pressure oil extraction systems (screw press and hydraulic press) are evaluated with regard to yield and quality parameters to obtain virgin pistachio oil. Yields were slightly higher when the screw press was used, especially with pistachios of the highest quality. However, although the screw press is considered as a cold extraction system, it requires the heating of the tip in order to obtain optimum performance, and the yield may be affected by the fluctuation in temperature, which leads to a higher variation in the yield.

Differences in the color of the oil were observed. The screw press produces darker oils than the hydraulic press due to the accumulation of Maillard reaction products derived from the higher 
Table 2

Induction time (hours) for the oils obtained from different types of pistachios extracted with the screw press and the hydraulic press. Values were obtained with the rancimat method, at a temperature of $100^{\circ} \mathrm{C}$ with an air flow of $10 \mathrm{~L} / \mathrm{h}$

\begin{tabular}{lcccc}
\hline \multicolumn{5}{c}{ Induction Time (hours) } \\
\hline Larnaka & A & B & C \\
\hline Screw & $47.07 \pm 1.19^{\mathrm{a}, \mathbf{a}}$ & $30.23 \pm 2.33^{\mathrm{a}, \mathbf{c}}$ & $33.12 \pm 0.49^{\mathrm{a}, \mathrm{bc}}$ & $36.91 \pm 1.48^{\mathrm{a}, \mathbf{b}}$ \\
Hydraulic & $47.76 \pm 4.70^{\mathrm{a}, \mathbf{a}}$ & $30.07 \pm 1.92^{\mathrm{a}, \mathrm{b}}$ & $30.21 \pm 1.29^{\mathrm{b}, \mathrm{b}}$ & $30.65 \pm 1.53^{\mathrm{b}, \mathbf{b}}$ \\
\hline
\end{tabular}

${ }^{a, b}$ Different letters in the same row indicate significant differences in the extraction system used $(p<0.05)$.

$a, b, c$ Different bold letters in the same line indicate significant differences among the pistachio types $(p<0.05)$.

The values represent the average and standard deviation of three replicates.

temperatures required by the screw press. In addition, the quality of the pistachios may affect the color of the oil obtained.

As for acidity, $\mathrm{K}_{270}$, and $\mathrm{K}_{232}$, no significant differences were observed in both systems when high quality pistachios are used to produce oil. Similar data were obtained for oxidative stability. When lower quality pistachios were used, the acidity, $\mathrm{K}_{270}$ and $\mathrm{K}_{232}$, values increased, especially in the screw press samples, while oxidative stability decreased.

\section{ACKNOWLEDGEMENTS}

The present work has been partially supported by the "Consejería de Agricultura y MedioAmbiente" of the "Junta de Comunidades de Castilla-La Mancha (Ref. COOP-2010/02/001)". In addition, the authors wish to thank the companies "Insobol", "Valseco S.L.", "Pistachos de la Mancha S.L.", the "InstitutoTécnico Agronómico Provincial de Albacete (ITAP)" and the "Centro de Mejora Agraria El Chaparrillo" for their participation and colaboration.

\section{REFERENCES}

Aguilera MP, Beltrán G, Ortega D, Fernández A, Jiménez A, Uceda M. Characterisation of virgin olive oil of Italian olive cultivars: 'Frantoio' and 'Leccino', grown in Andalusia. Food Chem. 89, 387-391.

AOAC. 1990. Official Methods of Analysis, 15th ed. Assoc. Off. Anal. Chem., Arlington, VA.

Arena E, Campisi S, Fallico B, Maccarone E. 2007. Distribution of fatty acids and phytosterols as a criterion to discriminate geographic origin of pistachio seeds. Food Chem. 104, 403-408.

Arranz S, Cert R, Pérez-Jiménez J, Cert A, SauraCalixto F. 2008. Comparison between free radicals scavenging capacity and oxidative stability of nut oils. Food Chem. 110, 985-990.

Awad AB, Fink CS. 2000. Phytosterols as anticancer dietary components: evidence and mechanism of action. J. Nutr. 130, 2127-2130.

Bellomo MG, Fallico B, Muratore G. 2009. Stability of pigments and oil in pistachio kernels during storage. Int. J. Food Sci. Tech. 44, 2358-2364.

Bensassi F, Rhouma A, Ghrab M, Bacha H, Rabeh Hajlaoui M. 2010. Evaluation of cultivar susceptibility and storage periods towards aflatoxin B1 contamination on pistachio nuts. Mycotoxin Res. 26 199-203.

CIE. 1986. Colorimetry. 2nd ed. Publication CIE no. 1 15, 2. Ed. Central Bureau of the Commission Internationale de L'Eclairage, Vienne

Conte $\mathrm{P}$, Mineo V, Bubici S, de Pasquale C, Aboud F, Maccotta A, Planeta D, Alonzo G. 2011. Dynamics of pistachio oils by proton nuclear magnetic resonance relaxation dispersion. Anal. Bioanal. Chem. 400, 1443-1450.

Durmaz G, Gökmen V. 2011. Changes in oxidative stability, antioxidant capacity and phytochemical composition of Pistaciaterebinthus oil with roasting. Food Chem. 128, 410-414.

EEC. 1991. Commission Regulation (EEC) No 2568/91 of 11 July 1991 on the characteristics of olive oil and olive-residue oil and on the relevant methods of analysis. Off. J. Eur. Comm. L248, 1-82.

Gentile C, Tesoriere L, Butera D, Fazzari M, Monastero M, Allegra M, Livrea MA. 2007.Antioxidant Activity of Sicilian Pistachio (Pistacia vera L. Var. Bronte) Nut Extract and Its Bioactive Components. J. Agric. Food Chem. 55, 643-648.

Ghrab M, Zribi F, Ayadi M, Elloumi O, Mnafki N, Ben Mimoun M. 2010. Lipid characterization of local pistachio germoplasm in central and southern Tunisia. J. Food Compos. Anal. 23, 605-612.

Gutiérrez F. 1989. Determinación de la estabilidad oxidativa de aceites de oliva vírgenes: Comparación entre el método A.O.M. y el método Rancimat. Grasas Aceites, 40, 1-5.

Kochhar SP, Henry CJK. 2009. Oxidative stability and shelf-life evaluation of selected culinary oils. Int. J. Food Sci. Nutr. 60, 289-296.

Lee Y-C, Oh S-W, Chang J, Kim I-H. 2004. Chemical composition and oxidative stability of safflower oil prepared from safflower seed roasted with different temperatures. Food Chem. 84, 1-6.

McGuire RG. 1992. Reporting of Objective Color Measurements. HortScience 27, 1254-1255.

Miraliakbari H, Shahidi F. 2008. Oxidative Stability of Tree Nut Oils. J. Agric. Food Chem. 56, 4751-4759.

Ostlund RE, Jr. 2004. Phytosterols and cholesterol metabolism. Curr. Opin. Lipidol. 15, 37-41.

Panahi, B, Khezri M. Effect of harvesting time on nut quality of pistachio (Pistacia vera L.) cultivars. Sci. Hortic. 2011, in press.doi: 10.1016/j.scientia. 2011.05.029

Pardo JE, Cuesta MA, Alvarruiz A. 2007. Evaluation of potential and real quality of virgin olive oil from the designation of origin "Aceite Campo de Montiel" (Ciudad Real, Spain). 2007. Food Chem. 100, 977984 
Pardo JE, Cuesta MA, Alvarruiz A, Granell JD, AlvarezOrtí M. 2011. Evaluation of potential and real qualities of virgin olive oil from the designation of origin (DO) "Aceite Montes de Alcaraz" (Albacete, Spain). Food Chem. 124, 1684-1690.

Park MH, Seol NG, Chang P-S, Yoon SH, Lee JH. 2011. Effects of Roasting Conditions on the Physicochemical Properties and Volatile Distribution in Perilla Oils (Perilla frutescens var. japonica). J. Food Sci. in press. doi: 10.1111/j.1750-3841.2011.02214.x

Phillips KM, Ruggio DM, Ashraf-Khorassani M. 2005. Phytosterol Composition of Nuts and Seeds Commonly Consumed in the United States. J. Agric. Food Chem. 53, 9436-9445.

Ros E. 2010. Health Benefits of Nut Consumption. Nutrients 2, 652-682.

Tavakolipour H, Armin M, Kalbasi-Ashtari A. 2010. Storage Stability of Kerman Pistachio Nuts (Pistacia vera L.). Int. J. Food Eng. 6, 1-13.

Tomaino A, Martorana M, Arcoraci T, Monteleone D, Giovinazzo C, Saija A. 2010. Antioxidant activity and phenolic profile of pistachio (Pistacia vera L., variety Bronte) seeds and skins. Biochimie 92, 1115-1122.

Tsantili E, Takidelli C, Christopoulos MV, Lambrinea E, Rouskas D, Roussos PA. 2010. Physical, compositional and sensory differences in nuts among pistachio (Pistacia vera L.) varieties. Sci. Hortic. 125, 562-568.

Uriarte PS, Goicoechea E, Guillén MD. 2011. Volatile components of several virgin and refined oils differing in their botanical origin. J. Sci. Food Agric. 91, 18711884.

Vaidya B, Choe E. 2011. Stability of Tocopherols and Lutein in Oil Extracted from Roasted or Unroasted Mustard Seeds During the Oil Oxidation in the Dark. Food Sci. Biotechnol. 20, 193-199.

Wijesundera C, Ceccato C, Fagan P, Shen Z. 2008. Seed roasting improves the oxidative stability of canola (B. napus) and mustard (B. juncea) seed oils. Eur. J. Lipid Sci. Technol. 110, 360-367.

Recibido: 31/10/11 Aceptado: $14 / 2 / 12$ 